\title{
E-BUSINESS COOPERATION DALAM PEMANFAATKAN MEDIA MIT APP INVENTOR DAN WEB BOOTSTRAP SEBAGAI PLATFORM UNTUK MENINGKATKAN KESEJAHTERAAN MASYARAKAT PROBOLINGGO
}

\author{
Moh. Ainol Yaqin ${ }^{1}$, Abdullah Al Anis ${ }^{2}$ \\ 1Teknik Informatika, Fakultas Teknik \\ Universitas Nurul Jadid, Paiton Probolinggo Jawa Timur, Indonesia \\ e-mail : ainolyaqin09@gmail.com \\ ${ }^{2}$ Humaniora, Fakultas Sosial dan Hukum \\ Universitas Nurul Jadid, Paiton Probolinggo Jawa Timur, Indonesia \\ e-mail : abdullah81alanisfauzi@mail.com \\ Diterima: 18 April 2019. Disetujui : 12 Juni 2019. Dipublikasikan : 30 Juni 2019 \\ (C)2019 -TESJ Fakultas Teknik Universitas Maarif Hasyim Latif. Ini adalah artikel dengan \\ akses terbuka di bawah lisensi CC BY 4.0 (https://creativecommons.org/licenses/by/4.0/)
}

\begin{abstract}
ABSTRAK
Lapangan pekerjaan pada zaman sekarang sangat sulit didapat sehingga beberapa orang atau kelompok membuat usaha sendiri atau disebut berwirausaha, penerapan kegiatan ini banyak diwadahi dalam bentuk Industri Kecil Menengah (IKM), Usaha Kecil dan Menengah (UKM) dan Pembinaan Kesejahteraan Keluarga (PKK). Akan tetapi kesulitannya adalah dalam segi pemasaran, produk yang unik dan bagus tidak banyak tahu sehingga daya jualnya minim dan laba tidak besar, produk tersebut merupakan potensi lokal yang tidak terjajah dan perlu dikembangkan. Dari permasalahan tersebut, dibuatlah aplikasi E-business Cooperation dengan Multi Produsen berbasis MIT App Inventor dan Web bootstrap, yang dapat membantu dan mempermudah dalam mewadahi produk untuk dikenalkan ke daerah-daerah di luar bahkan bisa go Internasional.. Aplikasi ini menggunakan dua media yaitu website diimplementasikan dengan Web Bootstrap dan berbasis android mobile dengan menggunakan MIT App Inventor. Dengan menggunakan dua media ini, dapat menyentuh segala aspek masyarakat yang sesuai dengan kebutuhan zaman globalisasi. Formulasi konsep teknologi ini, memberikan kemudahan pada pengguna, yaitu dapat mengelolah produk-produk tersebut dan mengetahui produk-produk yang sudah dibeli oleh konsumen. Dengan adanya aplikasi tersebut memberikan kemudahan pada pihak kedua yaitu multi-produsen dalam memasarkan dan mengontrol barang tersebut dengan mudah dan efektif, karena sistem menggunakan $E$ business Cooperation saling menguntungkan, membantu dan sama-sama meningkatan produk pada setiap multi-produsen.
\end{abstract}

Kata kunci: android , E-business Cooperation, MIT App Inventor, Multi-produsen, web

\section{PENDAHULUAN}

Krisis moneter telah menjadi momok yang selalu membayangi bangsa Indonesia, meski pada tahun 2009 Indonesia mengalami kenaikan pertumbuhan ekonomi. Akan tetapi kemiskinan, kerawanan pangan dan kekurangan gizi masih menjadi topik yang serius dan tetap dengan kesenjangan besar antara provinsi dan kabupaten (Valešová, Herák, Shinoda, Mazancová, \& Verner, 2017). Hal ini salah satunya disebabkan oleh Indeks Pembangunan Manusia (IPM) Indonesia masih berada di peringkat 113, turun dari posisi awal yaitu 110 sebelumnya. UNDP (United Nations Development Programme) mencatat, IPM Indonesia 2015 sebesar 0,689 dan berada di tingkat 113 dari 188 negara di dunia. IPM ini meningkat sekitar 30,5 persen dalam 25 tahun terakhir. Namun di saat yang bersamaan, UNDP melihat ada sejumlah indikator kesenjangan yang bertolak belakang dengan peningkatan IPM tersebut. Pertama, tingkat kemiskinan dan kelaparan. UNDP mencatat, ada sekitar 140 juta orang Indonesia yang hidup dengan biaya kurang dari Rp. 20 ribu per hari dan 19,4 juta orang menderita gizi buruk (Fauzi, 2017).

Pada saat ini penanangan yang efektif dengan menumbuhkan kewirausahaan, karena kewirausahaan telah diadopsi di seluruh dunia, sebagai strategi untuk memfasilitasi partisipasi ekonomi di antara anak muda (Gwija, Eresia-Eke, \& Iwu, 2014). Statistik pada Indonesia mempunyai kekuatan pada networking (Lloyd, 2018).

Pada kabupaten Probolinggo kewirausahan adalah IKM, UKM dan PKK, akan tetapi kesulitan di segi pemasaran dan mengenalan produk secara 
luas. Dengan Perkembangan Teknologi Informasi saat ini telah berkembang sangat cepat (Ariyani, Hanantjo, \& Purnama, 2015), media yang akan digunakan adalah internet sehingga semua tidak terbatas dengan tempat waktu, semua transaksi dapat dilaksanakan dengan efektif, efisien, tepat sasaran yang sustainability. Agar lebih mempermudah pihak kedua yaitu Multi Produsen tersebut pendidikan teknologi (Lazar, 2015) sangat penting untuk lebih mempermudah user dalam mengelola barangnya.

Maka dari itu, pembangunan aplikasi $E$ business Cooperation dengan Multi Produsen berbasis MIT App Inventor dan Web bootstrap, tentunnya hal tersebut memilik dampak bagi pengembangan kewirausahaan berbasis internet dan merupakan sebuah terobosan kreatif-inovatif untuk menjawab persoalan bangsa kita dari perekonomian. Karena aplikasi tersebut sebagai media pemasaran berbasis online, sesuai dengan kekuatan Kewirausahaan Indonesia 2018 adalah networking. Di mulai dari itu, daerah-daerah lain bahkan Negara luar tahu dengan produk-produk hasil industri sendiri yang tidak kalah bagus dengan barang impor.

\section{Penelitian Terkait}

Pemilihan penelitian terkait mengambil beberapa poin penting dari judul, yaitu tentang objeknya yaitu konsep dari e-Busniess, IKM dan UKM pada aplikasi dan ibu-ibu PKK yang dapat menghasilkan produk. Jurnal yang pertama tentang kepercayaan suatu bisnis jual beli online, yaitu " $A$ Meta-analysis of Online Trust Relationships in Ecommerce" (Kim \& Peterson, 2017). Jurnal ini menjelaskan peran kepercayaan online dalam perdagangan elektronik, dimana terdapat Analisis dari 16 hubungan berpasangan yang berasal dari 150 studi empiris yang melibatkan kepercayaan online mengungkapkan bahwa kepercayaan online memiliki signifikan pada beberapa hal misalnya privasi yang dirasakan, kualitas layanan yang dirasakan dan konsekuensi (misalnya, loyalitas, niat pembelian berulang). Meski demikian ada beberapa analisis tambahan yaitu tampilan dari web tersebut harus menarik dan user friendly.

Jurnal terkait berikutnya tentang IKM dan UKM (Chotimah \& Handayaningsih, 2017). Pedagangan adalah di bawah Disperindagkop DIY, akan tetapi dalam memberikan fasilitas terhadap IKM dan UKM masih belum maksimal sehingga dibuatlah sistem e-Commerce dengan menggunakan Zachman Framework yang menggunakan media Website sebagai wadahnya. Dan pengujian sistem tersebut untuk pengujian analisi mencapai $100 \%$ dan pengujian usability uji coba untuk responden pembeli nilai 3.3 mencapai 3.1 nilai IKM. Hal tersebut menunjukan kepuasaan masyarakat.

Selanjutkan tentang PKK (Purba, 2016), Awal mula pembuatan roti ubi talas oleh Ibu PKK desa Tanjung Gusta digunakan sendiri, pada saat lebaran atau hari besar lainnya, supaya dapat menambah penghasilan maka dibuatlah sistem online sebagai pemasaran dan dari kemasannya juga dibuat sebaik mungkin. Bukannya itu, ibu-ibu PKK diberikan pelatihan cara pemasaran online, hal tersebut membantu masyarakat dalam meningkatka perekonomian desa Tanjung Gusta.

Ketiga penelitian terkait tesebut jika dibandingkan dengan penelitian sekarang memilik beberapa pengembangan yang cukup meningkatkan perekonomian masyarakat Kabupaten Probolinggo. Di jurnal pertama jika kepercayaan konsumen menjadi salah satu modal kemajuan suatu bisnis atau e-Commerce, maka pada penelitian yang akan dilakukan ini kepercayaan pada pihak kedua yang sebagai produsen (IKM,

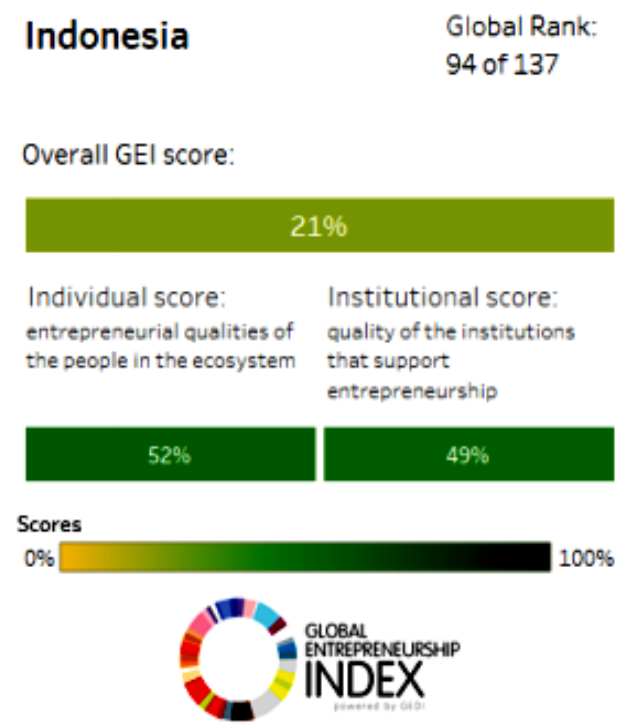

Strongest area:

Weakest area

Networking

Internationalization

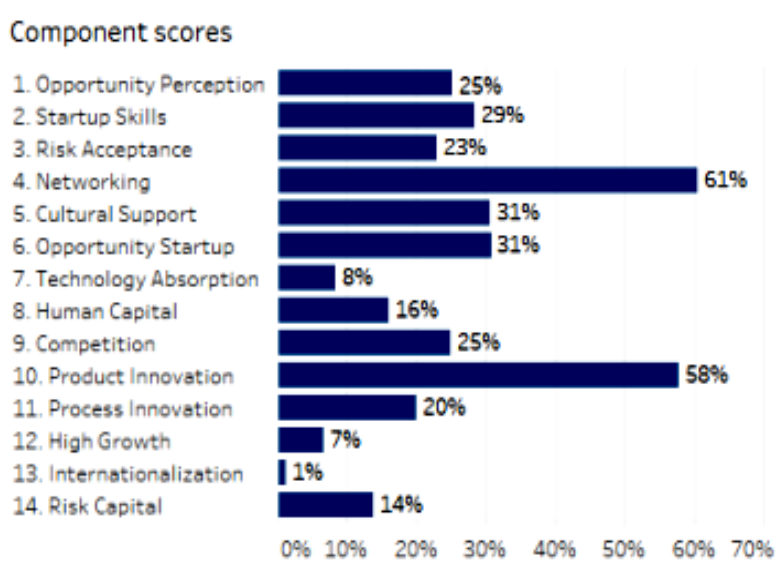

Gambar 1. Statistik Kewirausahaan Indonesia 2018 
UKM dan PKK). Dan kelebihan pada penelitian akan dilakukan dan masih belum ada pada kedua dan pada ketiga nyalah memperdayaan produsen IKM,UKM dan PKK yang sebagai administrator sehingga dapat mengelolah barang jualannya sendiri.

\section{E-busniess Cooperation}

Kata e-Busniess disebut dengan business networks adalah struktur yang sudah terbentuk secara nyata dimana sudah memiliki koneksi secara mekanisme (Lemmetyinen, 2010). Bentuk mekanismenya bisa menggunakan media internet baik network local maupun inter-koneksi. Cooperation adalah proses kerjasama baik secara internal organisasi, formal dan informal kondisi di suatu kegiatan dan memberian sikap harus secara seimbang mau berbeda sesuai dengan kesepatan awal (Lemmetyinen, 2010). Secara definisi maka, hemat kami E-Busniess Cooperation adalah suatu kerja sama secara kelompok atau individu yang mengutamakan keseimbangan keuntungan yang sebelumnya sudah ada kesepakatan antara pihak utama dan pihak kedua, dengan tujuan yang sama. Pihak kedua yang memberikan barang dan pihak pertama menyediakan platform sebagai media barang tersebut, atau biasa disebut dengan $e$ Commerce akan tetapi dengan skala yang lebih besar.

\section{Multi Produsen}

Pada Kamus Besar Bahasa Indonesia (https://kbbi.web.id/) multi adalah banyak; lebih dari satu; lebih dari dua. Dan produsen adalah penghasil barang. Secara harfiah hemat kami Multi produsen, sekumpulan penghasil barang dalam hal ini adalah IKM, UKM dan PKK yang sebelumnya sudah ada beberapa kesepakatan antara pihak pertama dan pihak kedua.

\section{MIT App Inventor}

MIT App Inventor adalah bahasa blok visual, yang yang memungkinkan pemula dan nonprogramer untuk membuat aplikasi untuk ponsel dan tablet (Wolber, Abelson, \& Friedman, 2015). Sistem pengkodingan dengan cara drag dan drop atau blok tinggal ditarik sesuai dengan keinginan tanpa mengetik. MIT APP Inventor ini akan digabungkan dengan aplikasi web bootstrap yang back end menggunakan Native PHP dan database mysql. Dengan menggunakan software memberikan kemudahan untuk mengembangkan android dari sistem yang akan dirancang ini dengan mudah dan gampang.

\section{Web Bootstrap}

Pada offisial web resmi bootsrap https://getbootstrap.com/, Bootstrap adalah framework front-end HTML, CSS, dan Javascript populer yang dirancang dan dibuat untuk mengembangkan situs web responsif. Dipenjelas dari suatu jurnal Bootstrap digunakan untuk membangun front end situs web yang menyediakan perilaku responsif (Shah, 2015). Syarat menggunakan Bootstrap harus menggunakan html 5, dan dilink-kan dengan framework yang dimiliki oleh bootstrap tersebut. Pembuat desain lebih cepat dan lebih mudah sehingga jika melakukan pengembangan front end akan lebih efisien, efektif dan cepat.

\section{METODE PENELITIAN}

Paragraf Metode penelitan yang digunakan untuk membangun sistem yang sudah membentuk E-business Cooperation dengan Multi Produsen (IKM, UKM dan PKK) dalam pemanfaatkan Media MIT App Inventor dan Web Bootstrap sebagai Platform untuk meningkatkan Kesejahteraan Masyarakat Probolinggo, Gambar 2.

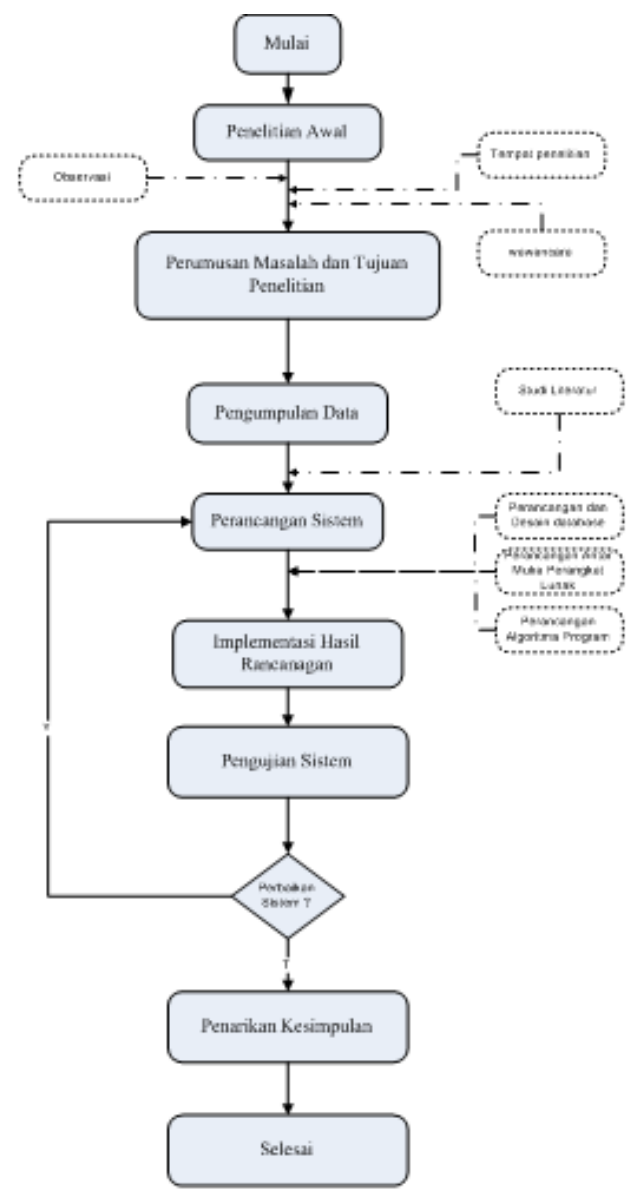

Gambar 2. Tahapan Metode Penelitian

\section{Penelitian Awal}

Penelitian awal akan dilakukan oleh ketua dan anggota penelitian di Perpustakaan Daerah Kab. Probolinggo dengan Bapak Hesti yang 
memang bagiannya adalah pada pengembangan IKM, UKM dan PKK di daerah Kab. Probolinggo. Di tempat tersebut akan melakukan wawancara dan observasi. Dari kedua kegiatan tersebut, wawancara telah dilakukan dan hasil wawancara tersebut ada beberap temuan yang membuktikan bahwa aplikasi E-business Cooperation dengan Multi Produsen (IKM, UKM dan PKK) dalam pemanfaatkan Media MIT App Inventor dan Web Bootstrap sebagai Platform sangat dibutuhkan, karena IKM, UKM dan PKK masih belum terwadahi terutama dalam bentuk pemasaran, pengawasan dan pengontrolan Multi Produsen tersebut. Pada bagian observasi, akan melakukan observasi ke beberapa tempat yang memiliki IKM, UKM dan PKK, tentunya setelah mendapatkan data-data tempat multi produsen tersebut yang tersebar di daerah Kab. Probolinggo.

\section{Perumusan Masalah dan Tujuan Penelitian}

Kegiatan ini dilakukan oleh ketua dan anggota penelitian. Dari hasil wawancara dan obsevasi pada penelitian awal, ada beberapa permasalahan yang harus diselesakan dengan sistem yang terorganisir dengan baik dan terencana. Proses yang ada pada saat ini IKM, UKM dan PKK masih manual penjualan dititipkan ke warung-warung dan ada beberapa yang memanfaatkan sosial media seperti facebook. Akan tetapi masih belum efektif dan pihak Perpusda tidak dapat mengontrol perkembangan Multi Produsen tersetbut. Sehingga laba yang didapat masih kurang memuaskan dan bahkan minim. Maka dari itu, dibuatlah suatu sistem yang memiliki kerja sama antara multi produsen dan pihak Perpusda, berbasis website dan android sehingga dapat dijangkau oleh semua kalangan baik dalam negeri ataupun luar negari. Tujuan dari pembuatan aplikasi tersebut memberikan kemudahan pada pihak multi produsen dalam memasarkan produknya dan bagi Perpusda dapat mengontrol perkembangan multi produsen di daerah Kab. Probolinggo

\section{Pengumpulan Data}

Pengumpulan data dilakukan oleh ketua dan anggota penelitian. Pengumpulan data pada bagian ini merupakan tindak lanjut dari wawancara dan observasi pada penelitian awal, yang ditunjang dengan studi literatur. Studi literatur merupakan kegiatan yang dilakukan untuk mempelajari dan memahami E-business Cooperation dengan Multi Produsen (IKM, UKM dan PKK) dalam pemanfaatkan Media MIT App Inventor dan Web Bootstrap sebagai Platform beserta progress report-nya, pengembangan sistem informasi, bahasa pemrograman PHP dan App Inventor, MySQL dan SQLite.

\section{Perancangan Sistem}

Proses perancangan Sistem dilakukan oleh ketua penelitian. Perancangan sistem yang dimaksud adalah perancangan sistem memahami E-business Cooperation dengan Multi Produsen (IKM, UKM dan PKK) dalam pemanfaatkan Media MIT App Inventor dan Web Bootstrap sebagai Platform secara konseptual. Perancangan sistem yang dimaksud meliputi tiga aspek penting yaitu (1) perancangan database sebagai basis penambangan data; (2) perancangan antar muka perangkat lunak yang dibangun dan (3) perancangan algoritma program.

\section{Implementasi Rancangan.}

Implementasi Rancangan dilakukan oleh ketua penelitian. Tahapan ini adalah pengkodingan aplikasi, yang sesuai dengan perancangan sistem. Sehingga terbangun sebuah aplikasi untuk menyelesaikan masalah dalam penelitian ini.

\section{Pengujian Sistem}

Ketua dan anggota penelitian melakukan kegiatan ini. Menguji aplikasi dengan cara uji coba sistem. Jika sesuai maka dilanjutkan jika tidak maka kembali perancangan sistem.

\section{Penarikan Kesimpulan}

Penarikan kesimpulan dilakukan oleh ketua dan anggota penelitian. Kesimpulan didapat dari aplikasi dan proses penelitian yang dilakukan dan tidak lanjut dari penelitian akan menjadi saran yang akan lebih dikembangkan lagi oleh penelitian berikutnya.

Indikator pencapaian dan target luaran penelitian ini adalah membuat aplikasi berbasis web android yang dapat mewadahi multiprodusen, dalam mempromosikan dan menjual hasil-hasil produknya ke masyarakat luas. Sehingga masyarakat dapat mengetahui dan dapat mengkonsumsinya. Dan multi-produsen mendapatkan laba, yang dapat mensejahterakan perekonomian secara berkelanjutan.

\section{HASIL DAN PEMBAHASAN}

Hasil akhir dari penelitian ini adalah aplikasi E-business Cooperation yang berbasis web dan MIT App Inventor. Akan tetapi sebelum ke pada interface website, ada yang penting yaitu desain dari database-nya, sistem database akan menggunakan sistem dari ERD (Entitas Relation Diagram). Kemudian alur sistem kerja aplikasi akan menggunakan contek diagram atau disebut dengan DFD (Data Flow Diagram) level 0, digunakan untuk alur besaran dari aplikasi ini, selanjutnya tampilan dari aplikasi website dan MIT 
App Inventor, lebih jelasnya berikut tahapantahapannya.

Secara normal aplikasi ini merupakan aplikasi e-Shopping yang dikembangakan usersnya. Karena pedagang menengah akan menitipkan barang-barangnya di platform ini,. Jadi terdapat dua pengelolah, pertama sebagai admin utama dan kedua adalah admin seller yang peran sebagai penitip barang untuk dijualkan.

\section{ERD (Entitas Relation Diagram)}

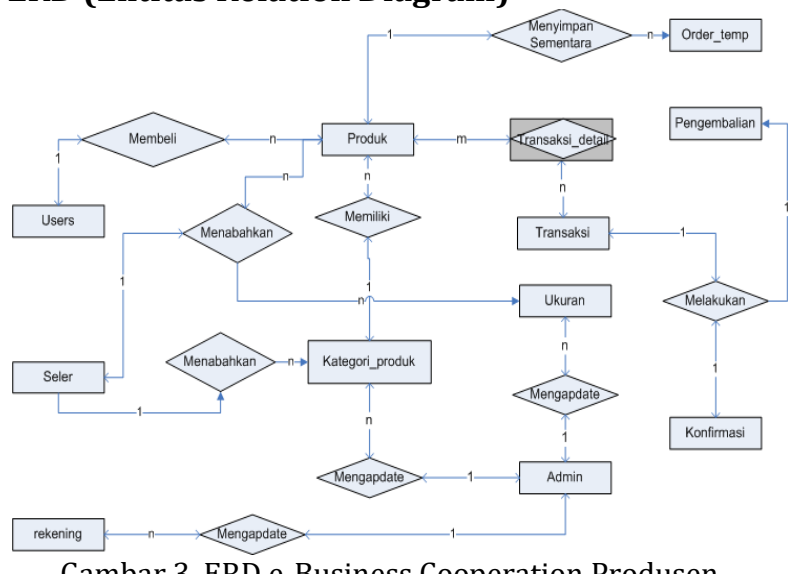

Gambar 3. ERD e-Business Cooperation Produsen

Kemudian Alur Data Flow Diagram (DFD), sebagai tindak lanjut dari desain database-nya.

\section{Data Flow Diagram (DFD)}

Secara normal aplikasi ini merupakan aplikasi e-Shopping yang dikembangkan users-nya. Karena pedagang menengah akan menitipkan barang-barangnya di platform ini, adapun dengan database-nya Gambar 4.

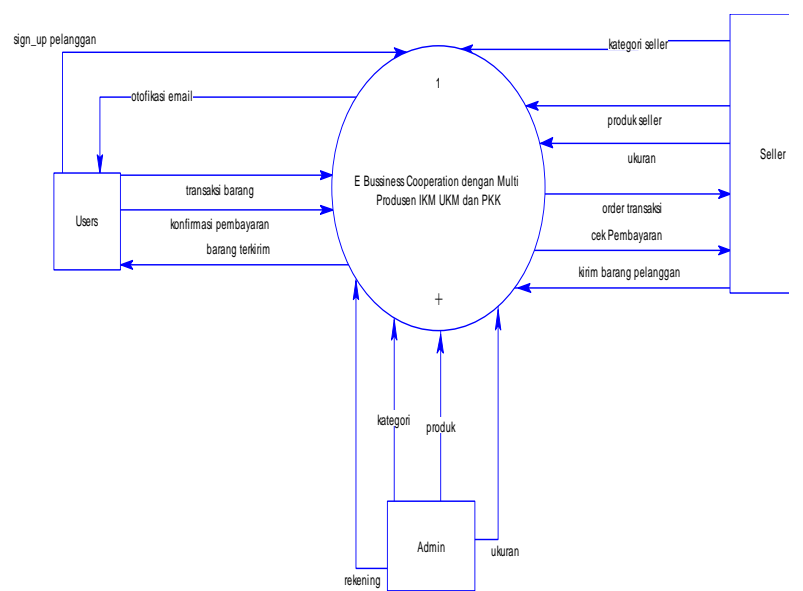

Gambar 4. DFD Level 0 atau Context Diagram e-Business Cooperation Produsen

Desain database dan Alur diagram tersebut sudah dapat merancang suatu website yang memliki relasi sesuai dengan kebutuhan. Kemudian desain dari aplikasi website yang terdiri dari website tampilan/interface, semua alur dari login, beranda sign up users, sign up seller, tampilan barang, keranjang, administrasi seller dan admin utama dan lainnya. Akan tetapi pada hal ini yang akan ditampilakan hanya intinya saja, yaitu halaman utama barang dan administrator dari seller, dimana sudah lengkap dengan menu yang dibutuhkna oleh sistem, lebih jelasnya ada pada simulasi interface Gambar 5.

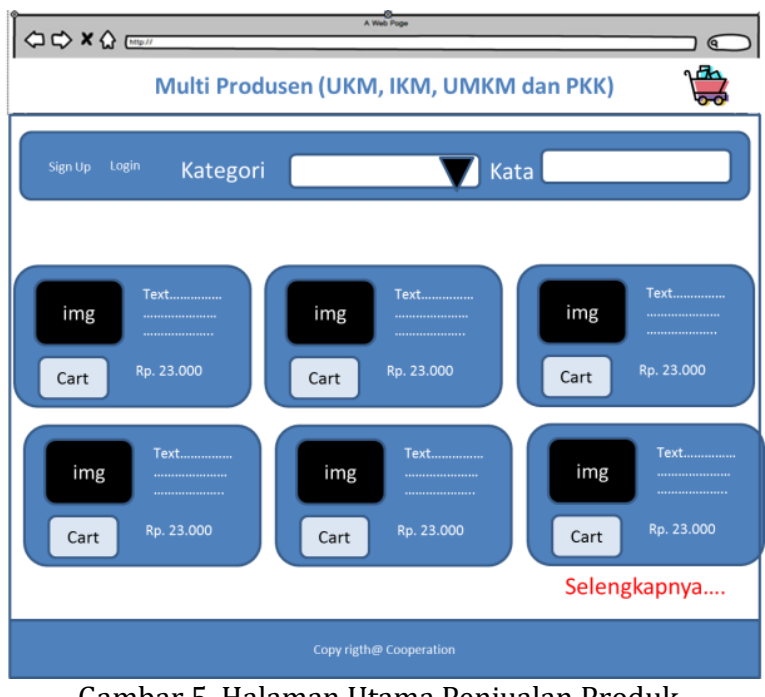

Gambar 5. Halaman Utama Penjualan Produk

Halaman utama penjualan produk terdapat filter pencarian dari kategori produk dan kata atau barang apa saja yang akan dicari. Menu sign up digunakan untuk mendaftar sebagai pelanggan. Login untuk membeli barang dengan sebelumnya sudah melakukan sign up. Jika membeli barang pilih tombol Cart dan untuk melihat detail pilih titik-titik pada tulisan di atas. Dan selengkapnya untuk melihat produk yang lebih banyak lagi

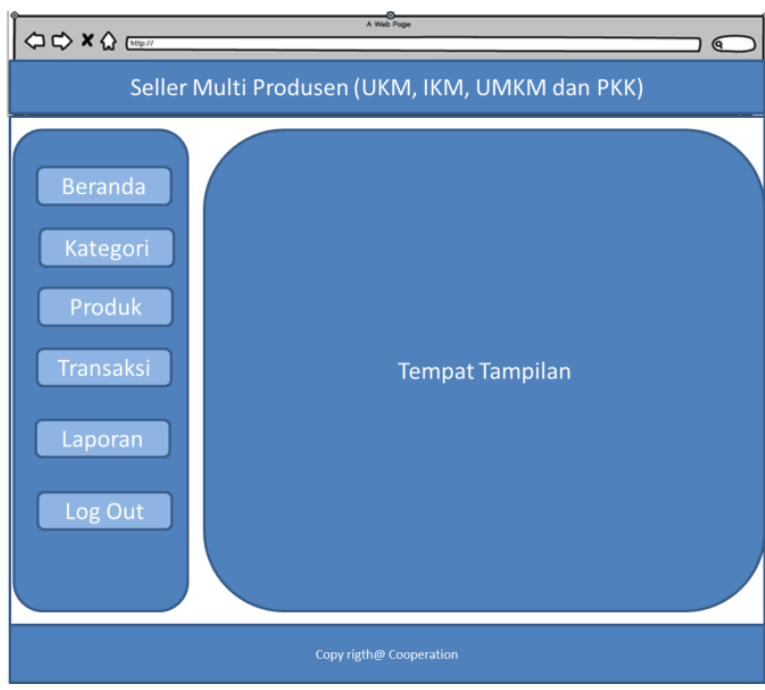

Gambar 6. Halaman Utama Administrator Seller

Halaman Seller dikhusukan untuk usahausaha menengah baik itu berupa UKM, IKM, UMKM dan PKK, pengaksesan seller diatur oleh admin utama. Jadi tidak semua orang dapat menjualkan 
barangnya di website ini, hanya khusus yang telah di data. Berikutnya adalah fungsi dari MIT App Inventor, sesuai dijelaskan $\mathrm{di}$ atas, tool ini merupakan drag dan drop aplikasi yang kental dengan devise atau perangkat, tool ini untuk mendata produk dan membaca QR code pada suatu produk, agar identifikasi produk dapat dikenal secara barcode dan memberikan kemudahan dalam mencari data secara offline.

\section{PENUTUP}

Kesimpulan dari penelitian memberikan kemudahan pada pengusaha menengah (UKM, IKM, UMKM dan PKK) di daerah Probolinggo dalam mengenalkan produk-produknya yang tidak banyak orang yang tahu. Karena Probolinggo terdapat banyak pengusaha menengah (UKM, IKM, UMKM dan PKK) yang berada di daerah plosok kabupaten Probolinggo, akan tetapi gaptek (gagap teknologi), maka dari itu dengan adanya aplikasi ini dapat membantu dalam memasarkan dan untuk mendapatkan laba semaksimal mungkin. Saran dari penelitian ini aplikasi perlu menggunakan atau mengupgrade sesuai dengan kecanggihan teknolgi seperti React Js, React Native, Vue Js dan database menggunakan no Sql seperti Monggo DB. Serta menggukan server secara total dalam mengimplementasikan aplikasi ini agar mengaksesan aplikasi lebih cepat dan baik.

\section{UCAPAN TERIMA KASIH}

Ucapan terima kasih yang paling utama adalah untuk Allah SWT, yang telah memberikan nikmat sehat, kedua kepada Nab Muhammad yang telah mengubah dari zaman ke kebodohan ke zaman intelektual yang kami rasakan saat ini. Kemudian terima kasih kepada Orang tua saya, sahabat-sahabat Fakultas teknik yang selalu memberikan dukungan moral dan moril. Terimakasih juga buat Bapak-Ibu IKM, UKM, UMKM dan PKK yang telah memberikan ijin untuk melakukan penelitian ini.

\section{DAFTAR PUSTAKA}

Ariyani, W., Hanantjo, D., \& Purnama, B. E. (2015). e-Commerce web development in wiga art. International Journal of Science and Research (IJSR), 4(5), 379-384.
Chotimah, S. E., \& Handayaningsih, S. (2017). Implementasi Zachman Framework untuk Pemodelan dan Perancangan Sistem ECommerce pada Sektor Perdagangan IKM. Telematika, 13(1).

Fauzi, Y. (2017, March). Ranking Indeks Pembangunan Manusia Indonesia Turun ke113. CNN.

Gwija, S. A., Eresia-Eke, C., \& Iwu, C. G. (2014). Challenges and Prospects of Youth Entrepreneurship Development in a Designated Community in the Western Cape, South Africa. Journal of Economics and Behavioral Studies, 6(1), 10-20. https://doi.org/10.5901/mjss.2014.v5n1p6 1

Kim, Y., \& Peterson, R. A. (2017). A Meta-analysis of Online Trust Relationships in E-commerce. Journal of Interactive Marketing, 38, 44-54. https://doi.org/10.1016/j.intmar.2017.01.0 01

Lazar, S. (2015). The importance of educational technology in teaching. International Journal of Cognitive Research in Science, Engineering and Education, 3(1).

Lemmetyinen, A. (2010). The coordination of cooperation in tourism business networks.

Lloyd, A. (2018). Zoltán J. Ács László Szerb Ainsley Lloyd. The Global Enterpreneuship Index.

Purba, M. (2016). Kemasan dan Pemasaran Online Roti Ubi Talas dalam Rangka Menambah Penghasilan Ibu-Ibu PKK Tanjung Gusta. JIPN Uournal of Informatics Pelita Nusantara), 1(1), 24-27.

Shah, M. Q. (2015). Responsive Web Development using The Twitter Bootstrap. Bachelor's Thesis Degree Programme: Information Technology Specialisation: Internet Technology 2015, 1-42.

Valešová, L., Herák, D., Shinoda, K., Mazancová, J., \& Verner, V. (2017). The nexus between food insecurity and socioeconomic characteristics of rural households in Western Indonesia identified with Food and Nutrition Technical Assistance's approach by USAID. Agronomy Research, 15(3), 921-934.

Wolber, D., Abelson, H., \& Friedman, M. (2015). Democratizing computing with app inventor. GetMobile: Mobile Computing and Communications, 18(4), 53-58. 